\title{
¿Cómo cultivar la originalidad en la escuela primaria rural?
}

How to cultivate originality in rural primary school?

\author{
María Fidelia Díaz Reyes \\ e-mail: fideliad@uo.edu.cu \\ Universidad de Oriente. Cuba
}

Estrella Margarita Lardoeyt Llauradó

e-mail: estrella.lardoeyt@gmail.co

Universidad de Oriente. Cuba

\section{Resumen}

Objetivo: diseñar una metodología que contribuya al desarrollo de la originalidad en la producción de textos escritos en los escolares de la escuela rural. Resultados: la manera observada de abordar los contenidos sobre producción de textos escritos no favorece el desarrollo de la originalidad. Se propone una metodología que consiste en el tratamiento de los contenidos de producción de textos escritos desde una perspectiva comunicativo-funcional, con el empleo del mencionado enfoque, que fue satisfactoriamente valorada por especialistas. Conclusiones: una metodología basada en el enfoque cognitivo, comunicativo y sociocultural para la enseñanza de la producción de textos escritos desde la asignatura de Lengua Española contribuye al desarrollo de la originalidad.

Palabras clave: originalidad; producción; textos escritos; escuela primaria rural.

\section{Abstract}

Objective: to design a methodology that contributes to the development of originality in the production of written texts in schoolchildren in the rural schools. Results: the observed way of approaching the contents on the production of written texts does not favour the development of originality. A methodology is proposed that consists of the treatment of the contents of written text production from a communicative-functional perspective, using the aforementioned approach, which was satisfactorily valued by specialists. Conclusions: A methodology based on the cognitive, communicative, and sociocultural approach for teaching the production of written texts from the Spanish Language course contributes to the development of originality.

Keywords: originality; production; written texts; rural primary school.

Recibido / Received: 15-06-2020

Aceptado / Accepted: 06-11-2020

Publicado en linea / Published online: 22-12-2020

Cómo referenciar este artículo / How to reference this article:

Díaz Reyes, M. F., \& Lardoeyt Llauradó, E. M. (2021). ¿Cómo cultivar la originalidad en la escuela primaria rural? Tendencias Pedagógicas, 37, pp. 75-89. doi: 10.15366/tp2021.37.007 


\section{Introducción}

El proceso de enseñanza-aprendizaje de la lengua materna se concreta desde los primeros grados de la escuela primaria a través de la asignatura de Lengua Española, la cual contribuye al desarrollo de la competencia comunicativa en los escolares mediante las habilidades comunicativas: leer, hablar, escuchar y escribir, para poder entender las demás asignaturas. La producción de textos escritos, como parte de uno de los componentes de esta asignatura, es el dominio cognitivo que resulta trabajoso enseñar por los maestros y de asimilar por los escolares; tanto es así que necesita de un perfeccionamiento mayor de su didáctica y su implementación práctica en la formación permanente del maestro primario, y constituye una temática de progresiva actualidad.

Resaltan los aportes ofrecidos por las investigadoras cubanas: A. Roméu (1997) e I. Domínguez (2006), quienes en las últimas décadas del siglo XX y principios del XXI tratan la producción de textos escritos en la enseñanza media y en la media-superior con el enfoque comunicativo y las teorías de la lingüística textual. Por otra parte, la aparición del enfoque cognitivo, comunicativo y sociocultural de la enseñanza de la lengua y la literatura, aportado por A. Roméu y colaboradores $(2003,2007)$, instituye los principios para el trabajo con los componentes funcionales de la lengua: comprensión, análisis y construcción.

En las indagaciones realizadas desde esta investigación no se ha encontrado ninguna investigación de índole nacional e internacional que haya centrado la atención en el desarrollo de la originalidad en un proceso integrado de producción de textos escritos considerando un modelo de texto. Lo antes expuesto incita a expresar que ello se logra con la reflexión didáctica del maestro para su orientación efectiva con vistas a que los escolares realicen el discernimiento de la integración de los saberes, desde la integración del proceso a través de un modelo de texto, con el nuevo enfoque. En las indicaciones teórico-metodológicas, que se ofrecen al maestro en las Orientaciones Metodológicas y en el Folleto sobre los ajustes curriculares, que expresan los requerimientos de los objetivos del programa, se acota considerar a la originalidad como un aspecto a evaluar en la producción de textos escritos.

El avance científico-tecnológico y los disímiles acontecimientos que se manifiestan en la sociedad han influido en los textos escritos para presentes y futuras generaciones. Por consiguiente, desde la ciencia del lenguaje se da una mirada para contribuir con el desarrollo de la dimensión lingǘstica del hombre y ejercer un efecto positivo sobre la didáctica de la lengua.

Según el Diccionario de la Real Academia Española, Vigésimo segunda edición (2010), la creatividad es la «facultad de crean», que es producir algo de la nada, establecer, fundar, introducir por primera vez una cosa; hacerla nacer o darle vida, en sentido figurado. Se piensa con ideas novedosas, con transformación, descubrimiento y redescubrimiento.

Por otro lado, el mismo diccionario define la originalidad como: actitud, comportamiento o acción originales, fuera de lo común. Está relacionada con el estilo personal de innovar de manera peculiar con imaginación creadora; de ahí su relación estrecha con la creatividad. A primera vista, creatividad y originalidad parecen conceptos iguales, pero desde esta perspectiva se considera que ser original es una actitud, un comportamiento que está fuera de lo común y va más allá de crear algo de la nada. Una actitud implica una cualidad, un modo, o un estilo.

A. Olivares (2015) comenta que para ser creativo es esencial potenciar esa «musa» nombrada inspiración que permite viajar por los senderos más inexplorados de la mente abandonando los miedos que la conservan enclaustrada. La creatividad está íntimamente relacionada con la originalidad; la primera es un proceso o habilidad mental que permite el hallazgo de respuestas innovadoras a problemáticas o necesidades con maneras novedosas de expresión y comunicación. La originalidad constituye una forma distintiva de crear una nueva y única idea que se distingue entre las demás.

A partir de la fundamentación epistemológica del tratamiento a la originalidad para la producción de textos escritos en la Educación Primaria se toman en cuenta consideraciones que permiten el planteamiento de una definición: «En los textos escritos por los escolares de sexto grado la originalidad está dada por la expresión de las vivencias, introducción de ideas sobre un tema propuesto o libre, de forma armónica, novedosa, espontánea, con independencia y autenticidad a partir de sus reflexiones, motivaciones y la concentración que el tema les inspira y que se manifiesta en la singularidad estilística y la belleza textual», M. F. Díaz (2012, p. 42).

La producción de textos escritos con originalidad ocupa un papel de primer orden por ser, a la vez, finalidad de enseñanza y recurso de aprendizaje; es una práctica social que rebasa las fronteras de la escuela y está determinada por las exigencias de la actividad y la comunicación del escolar. Aún 
no se han establecidos los indicadores para desarrollar la originalidad y ello agudiza más la dificultad para incorporar los propósitos reales de la producción de textos escritos en la escuela.

En el texto escrito se presenta la originalidad ajustada al tema con una expresión individual, con sello personal y presencia de características singulares en la elaboración o arreglos, así como relevancia y exigencia de un grado común de actitudes artísticas, emociones, pensamientos y formas lingüísticas que impregnan un estilo completamente individual. Además de innegables rasgos de personalidad, la motivación juega un papel significativo en la originalidad.

Los estudios apuntan que la motivación intrínseca (es decir, curiosidad...) contribuye positivamente a la originalidad, mientras que la motivación extrínseca (premios y elogios de los padres o maestros) a veces se vincula negativamente con la creatividad. (Amabile, 1989). Se coincide con dicho autor debido a que es necesario que prevalezca la actividad, la comunicación y la motivación intrínseca durante la producción del texto original por parte del escolar.

Los aspectos antes señalados, desde los fundamentos teóricos y en la orientación intencional de la originalidad de los textos escritos en las referidas indicaciones, constituyen posiciones de partida que justifican la necesidad de la investigación.

Por todo lo anteriormente expuesto se desarrolla esta investigación pedagógica sobre el proceso de enseñanza-aprendizaje de la asignatura de Lengua Española, que se imparte en la Educación Primaria, desarrollada en la carrera Licenciatura en Educación Primaria de la Facultad de Ciencias Pedagógicas correspondiente a la Universidad de Oriente, durante el curso 2018-2019 y que incluyó a un grupo de 20 escolares de quinto grado de una escuela primaria rural nombrada Frank País García, que está ubicada en el municipio de San Luis de la provincia de Santiago de Cuba, y el maestro de quinto grado, lo que representa el $100 \%$. Se persigue como objetivo: diseñar una metodología que contribuya al desarrollo de la originalidad en la producción de textos escritos.

\section{Métodos}

La metodología aplicada está estructurada en cuatro etapas: Etapa I: Diagnóstico, Etapa II: Sensibilización y preparación, Etapa III: Implementación y Etapa IV: Valoración.

Las etapas que se proponen sirven para el trabajo de autopreparación del maestro y su preparación metodológica.

Etapa I: Diagnóstico

Objetivo: Diagnosticar las debilidades y potencialidades del maestro para el desarrollo de la originalidad en la producción de textos escritos en los escolares de quinto grado.

El diagnóstico de la preparación del maestro permite la valoración individualizada de sus modos de actuación a través de la actividad y la comunicación evidenciada en la zona de desarrollo actual y la Zona de Desarrollo Próximo (ZDP), focalizando el enfoque socio-histórico cultural de Vigotsky y sus seguidores (1979) en su concepción teórica.

Procederes metodológicos

a) Seleccionar los sujetos, procesos e instrumentos.

b) Determinar los instrumentos para el diagnóstico.

c) Determinar las necesidades, logros, dificultades, potencialidades y fortalezas.

Recomendaciones metodológicas

Para dar cumplimiento a las acciones del proceder metodológico de esta etapa, se tiene en consideración el realizar las observaciones a clases y la revisión de documentos a la maestra de quinto grado y la aplicación de una entrevista a la misma, que hubo de ejecutarse por un directivo de la escuela previamente seleccionado.

El diagnóstico exploratorio aplicado a la maestra propicia la comprobación de los conocimientos, las habilidades y las capacidades fundamentales desarrolladas; además, se determina su nivel de preparación teórica y metodológica para dirigir el proceso de producción de textos escritos y así potenciar la originalidad en los escolares. De esta manera, se establecen sus necesidades, logros, dificultades, potencialidades y fortalezas.

Etapa II: Sensibilización y preparación

Objetivo: Formar al maestro para la implementación de la metodología.

Procederes metodológicos

a) Diagnosticar el estado real de originalidad de la producción de textos escritos de los escolares.

b) Estudiar la caracterización psicopedagógica del escolar de quinto grado. 
c) Determinar los contenidos, medios y formas de evaluación que deben respaldar los procedimientos, a partir de los objetivos previstos en la unidad temática.

d) Preparar teórica y didácticamente al maestro para el desarrollo de la originalidad, en un proceso integrado de la producción de textos escritos, desde la asignatura Lengua Española.

e) Recepcionar los problemas comunicativos del escolar, con énfasis en los que corresponden con la producción de textos escritos.

f) Estudiar la unidad temática a través del análisis, por parte del maestro, del programa, las orientaciones metodológicas y las adecuaciones curriculares del grado.

g) Acopiar los materiales teórico-metodológicos y bibliográficos para el trabajo encaminado al desarrollo de la originalidad en la producción de textos escritos.

h) Analizar el desarrollo de la originalidad en la producción de textos escritos de los sujetos que intervienen en el proceso.

i) Ejecutar talleres metodológicos para: el análisis del tratamiento de la originalidad en la producción de textos escritos, desde la asignatura Lengua Española en la Educación Primaria, el desarrollo de habilidades para el uso del método de análisis discursivo-funcional y su adecuación didáctica para el desarrollo de la originalidad en la producción de textos escritos, desde la asignatura Lengua Española en la Educación Primaria, y la discusión sobre la metodología en un proceso integrado a partir de un modelo de texto.

\section{Recomendaciones metodológicas}

Los resultados de la aplicación de una prueba pedagógica de entrada a los escolares y una entrevista grupal propician el conocimiento del estado actual del desarrollo de la originalidad en la producción de textos escritos.

Se recomienda rediseñar el tratamiento que debe dársele al desarrollo del proceso de producción de textos escritos, toda vez que escasean objetivos y contenidos dirigidos a dicho proceso integrado para el desarrollo de la originalidad. Ello permite al maestro la apreciación de la limitación que existe en este sentido.

La preparación docente se vincula a la dimensión Reflexión para la dirección productiva del texto escrito para el desarrollo de la originalidad en dependencia de sus propósitos, a saber: la organización de la unidad temática, la selección de los textos para las situaciones comunicativas, la elaboración de las actividades de comprensión lectora con vista al desarrollo del comportamiento creativo del escolar, encaminado a organizar respuestas originales y novedosas frente a una situación determinada o problema que debe resolverse, dejando de lado soluciones conocidas y buscando alternativas de solución que lleven a nuevos resultados o nuevas producciones.

Se sugiere el programa a través de los talleres siguientes:

Taller 1. El tratamiento de la originalidad en la producción de textos escritos, desde la asignatura Lengua Española en la Educación Primaria, con el objetivo de: Analizar las principales problemáticas en relación con el tratamiento de la originalidad en la producción de textos escritos, desde la asignatura Lengua Española en la Educación Primaria.

Taller 2: El método de análisis discursivo-funcional. Dimensiones y procedimientos para su contribución al desarrollo de la originalidad en la producción de textos escritos. Exigencias y perspectivas pedagógicas, con el objetivo de: Entrenar a los docentes en relación con el empleo pedagógico del método de análisis discursivo-funcional para el desarrollo de la originalidad en la producción de textos escritos, desde la asignatura Lengua Española en la Educación Primaria.

Taller 3: La metodología para el desarrollo de la originalidad en la producción de textos escritos, desde la asignatura Lengua Española en la Educación Primaria, con el objetivo de: Analizar, de conjunto con los docentes, lo referido a la metodología para el desarrollo de la originalidad en la producción de textos escritos, desde la asignatura Lengua Española en la Educación Primaria.

Todas las acciones de los procederes metodológicos de las etapas I y II se producen atendiendo al procedimiento propedéutico y de adiestramiento.

A partir de la etapa que aparece a continuación, la metodología se enrumba hacia la perspectiva del escolar. De modo que en los próximos párrafos, se hace corresponder con la dimensión Intuición innovadora para la producción del texto escrito. Constituyen procedimientos fundamentales que sirven de soporte a la adecuación didáctica del método de análisis discursivo-funcional los siguientes: análisis, observación, lectura en silencio, lectura oral (expresiva, selectiva, comparada, ejemplificación, diálogo, explicación, demostración) y los aportados por M. F. Díaz (2012, p. 84-86) que se declaran a continuación: 
a) Estimulación heurística: se pretende asimilar la información semántica del texto mediante el desarrollo del pensamiento reflexivo para lograr una estimulación sensorial con el uso de elementos lingüístico-literarios a través de estímulos gráficos y planteamientos de situaciones comunicativas propiciando conformar representaciones mentales, asimilar conceptos y valores que apuntan hacia el desarrollo del pensamiento creador con innovaciones.

Con la aplicación de dicho procedimiento se promueven relaciones armónicas entre maestrogrupo y escolar-grupo, así como un equilibrio entre el desempeño colectivo de los escolares, considerando que prevalezca el espíritu innovador en la comunicación por escrito de sus ideas portadoras de recursos lingüísticos matizados de originalidad. Para lograr esto, el maestro debe plantear impulsos con claridad e inteligencia en los escolares, en el momento preciso.

b) Innovación textualizada: se caracteriza por la búsqueda en el texto de lo nuevo o singular que refiere el autor y su correspondencia con lo vivencial y experiencial. Su uso se presenta, a partir de la selección léxico-sintáctico y textualizada de la información acopiada para saber conocer, saber hacer y saber ser durante la producción de textos escritos, teniendo como base su cultura local. Todo ello posibilita que los escolares produzcan mejores textos interesantes, significativos, con claridad, coherencia y con recursos generados de su invención.

c) Triangulación de saberes: se caracteriza por el hallazgo de expresiones creadas originales y bellas a partir del texto leído y asignado. Se refiere a los saberes que interactúan sobre la base de la orientación dirigida por el docente a través de indicaciones, explicaciones, impulsos heurísticos para favorecer al escolar la búsqueda, la selección, la exploración, las anotaciones libres, el desarrollo del pensamiento creador y el lenguaje, para la invención de recursos: estilísticos, morfosintácticos, textuales, entre otros, en función de una creación literaria original.

\section{Etapa III: Implementación}

Objetivo: Contribuir al logro de un desempeño metodológico del maestro con ajuste al desarrollo de la originalidad en la producción de textos escritos, atendiendo a los procederes metodológicos.

Se realiza la operacionalización con el texto que se va a producir; esto es, que el docente toma como punto de partida un modelo de texto que será re-creado de manera colectiva, sobre la base de re-escribir las ideas que en él aparecen hasta producir su propio texto.

Procederes metodológicos

a) Identificación con el modelo de texto que se va a producir

En diálogo con el maestro, los escolares analizan el modelo de texto, descomponiéndolo en sus rasgos característicos, y mediante la estimulación heurística (preguntas abiertas, impulsos heurísticos), el maestro los llevará a la comprensión de cuáles de estos rasgos son esenciales. Darán respuestas a las actividades orientadas por el maestro; determinarán el orden y los procedimientos para comprender y analizar el texto. Así reconocen las características fundamentales del modelo de texto.

b) Re-creación de un modelo de texto escrito con originalidad, de manera colectiva

Su propósito es re-crear la originalidad del modelo de texto presentado, de manera colectiva. Ello favorece que los escolares, sobre la base del trabajo realizado en la etapa anterior, reconstruyan el texto seleccionado.

Se lee el texto, si es un poema, por versos; si es prosa, por oraciones, para transformarlo. A medida que los escolares lean, van construyendo significados con el apoyo de sus experiencias y los conocimientos que tienen para re-crearlo. Se dará tiempo para aclarar y estructurar las ideas. Determinan, guiados por el maestro, los elementos que deberá contener cada uno de los rasgos esenciales del modelo de texto para que sea comprensible por otras personas. En calidad de elementos de los rasgos esenciales, se enfatiza en las partes y los recursos innovados.

Los escolares buscan el significado de las palabras, frases, recursos expresivos empleados por el autor o autores de la obra por contexto o por el diccionario, para interpretarlos, apreciar su belleza y la de las palabras empleadas; qué dice el emisor o autor, y para quién se escribe; todo ello bajo la guía del maestro. Cada escolar debe entender que sin la coherencia de las ideas no se logra la comunicación escrita.

Mediante el procedimiento de innovación textualizada los escolares desarrollan la imaginación reconstructiva a través de la creación de imágenes mentales, efectúan nuevas reestructuraciones, experimentan con nuevos sustitutos; transforman y permutan relaciones; reorganizan el modelo con flexibilidad, y siempre sujeto a las recomendaciones e ideas que surgen del colectivo en ese proceso de indagación constante.

c) Producción individual del texto escrito del mismo tipo del modelo 
Permite la aplicación de los conocimientos adquiridos a través del análisis del texto seleccionado. Aquí no expresa el maestro orientaciones especiales, sino que los escolares deben escribir con el fin de comunicar su forma peculiar de percibir la vida con la belleza textual propia de su estilo. Ello estimula, por otra parte, la explotación de las posibilidades creativas sin rigidez y la exploración del lenguaje para inventar hasta alcanzar una elaboración textual innovadora. Se deben potenciar las tres etapas en el proceso de escritura: la preescritura, la escritura y la reescritura.

d) Evaluación de los textos escritos creados con originalidad

Su propósito es evaluar el resultado logrado por los escolares en la producción de textos escritos originales, mediante el desarrollo de la expresión cognitivo-recíproca durante la interacción entre el maestro y los escolares. La evaluación desarrolla en los escolares sus capacidades del saber, saber hacer y del ser. Con ella se propicia el desarrollo de las diferentes formas de participación: autoevaluación, coevaluación y heteroevaluación.

Para medir el comportamiento de la producción de textos escritos en un proceso integrado, según M. F. Díaz (2012) se pueden utilizar los siguientes:

- Comprensión del texto modelo (Nivel I, Nivel II, Nivel III)

- Construcción textual

* Uso de los elementos de coherencia:

Lineal: clasificación de las ideas (CI) y enlace de una idea con otra (EI). Global: concordancia entre artículo y sustantivo (CAS), sustantivo y adjetivo (CSA), sujeto y verbo (CSV) y, engarce y delimitación adecuada de las oraciones (DO) y los párrafos (DP).

Formal: Empleo de los recursos conectores (ERC), estructuras gramaticales (EEG) y maneras de establecer los vínculos, selección del vocabulario.

* Sentido pragmático: relación del texto con el contexto (RTC), propósito de la construcción

(PC), reconocimiento y adecuación en correspondencia con la tarea comunicativa (RATC).

* Presentación: Márgenes (M), limpieza (L).

* Ortografía: Utilización de las mayúsculas y los diferentes grafemas, y de los signos de puntuación.

* Comportamiento de la originalidad:

Para evaluar la originalidad en los textos escritos se proponen las siguientes dimensiones: singularidad estilística y bellezas textuales aportadas por M. F. Díaz, (2012).

I. Singularidad estilistica: Distingue a la originalidad y esta, a su vez, debe considerarse equivalente a la muestra de la individualidad creativa. El escritor es original cuando es él mismo sin copiar a nadie. La singularidad estilística se nutre de la relación de lo léxico-semántico (palabras y su significado) con la sintaxis (función y las relaciones de las palabras y de las oraciones). Ello facilita manifestar cómo se dice con la expresión del pensamiento por escrito a través de las palabras, que son las etiquetas de las ideas.

2. Belleza textual

La belleza textual lleva consigo el carácter estético del texto escrito, lo cual se revela al: mostrar interés por transmitir el gusto estético; plasmar fuerza de expresión, corrección de las ideas expuestas, gracia, suavidad de color, legibilidad de las letras en el texto escrito.

Para medir la singularidad estilística y la belleza textual, desde este trabajo se proponen determinados indicadores, como sigue a continuación:

La singularidad estilística (SE) se trasmite en el texto escrito:

1. Si conservan los atributos individuales en el texto: significa expresión de las partes esenciales del tipo de texto.

2. Si expresa el tema con espontaneidad: se refiere a que el escrito esté impregnado de naturalidad y sencillez, de manera que las palabras y las frases respondan a las exigencias del tema.

3. Si escribe ideas con un poder imaginativo y plena conciencia de lo expresado con armonía: está encaminado establecer en el texto lo imaginario a través de la transposición de la realidad con la presencia del uso de recursos estilísticos.

4. Si introduce novedades: se relaciona con el carácter novedoso de todo el texto mediante lo propio y lo nuevo, así como la creación de recursos estilísticos y frases.

5. Si lo expresado tiene lógica: Es la organización razonada de las partes de un texto que tributa a lo que se trasmite (coherencia), la cual se apoya en las relaciones sintácticas que se establecen entre los 
elementos del texto (cohesión) y en su totalidad entre la forma (caudal léxico, en la sintaxis, en los recursos expresivos...) con el contenido (ideas elaboradas).

6. Si hace conexiones y distinciones entre las ideas y las cosas: significa las conexiones remotas y la organización de la variedad de ideas del texto con cualidades tales como: equilibrio, orden, concisión y claridad.

La belleza textual (BT) se expresa en el texto escrito:

1. Si transmite gusto estético: está relacionado con la percepción y la sensibilidad emocionales, así como la apreciación intelectual y los sentimientos estéticos que se van formando en el escolar durante el proceso de la producción del texto escrito, para así ir potenciando los juicios personales a partir de sus conocimientos, sus vivencias y experiencias sobre el tema que va a escribir con un gusto estético adquirido.

2. Si plasma fuerza de expresión: cuando el escolar muestra su mundo interior durante la creación de sus propias imágenes durante las percepciones del texto para la apropiación del contenido y la forma del texto escrito. De este modo, se crea su imagen sensorial a través del pensamiento representativo; se favorece además el desarrollo de la imaginación creadora los sentimientos, las emociones y el lenguaje durante la comunicación escrita.

3. Corrección de las ideas expuestas: se desarrolla cuando el escolar desde la elaboración del borrador y también de la reescritura del texto escrito realiza la autorevisión en cuanto a los niveles: sintáctico, léxico, morfosintáctico y estilístico. Es el momento en que el maestro llama la atención sobre el vocabulario, la estructura del texto, el estilo, la erradicación de los errores de expresión, la ortografía, la caligrafía, entre otros. En la revisión colectiva, el maestro contribuirá a dar solución a los errores comunes en el grupo.

4. Suavidad de color: está referida a dar el matiz adecuado durante la expresividad de las imágenes mediante la representación de detalles y objetos complementarios con una idea consciente. Ello se logra a través del desarrollo de las percepciones y los sentimientos estéticos por parte del escolar en la selección de los detalles para el desarrollo del tema. Se expresa en el texto en la delicadeza, la armonía y claridad de las ideas.

5. Gracia: está dada por la forma de expresión de los personajes de acuerdo con los tipos de textos. Se manifiesta en la simpatía a través de una expresión asequible y sin rebuscamientos.

6. Legibilidad de las letras: se relaciona con factores tales como: la inclinación, la forma y el espaciado de las letras en el texto.

e) Socialización y divulgación de los textos escogidos

La socialización y la divulgación de los modelos de textos creados por los escolares en diferentes espacios tales como: presentación en actos político-culturales, concursos en las diferentes instancias, talleres de creación literaria, boletines, revistas infantiles, entre otros, permite operar con los modelos en situaciones nuevas y variadas.

\section{Resultados}

El presente trabajo se ajustó a la metodología aportada por M. F. Díaz (2012), la cual fue aplicada con escolares de quinto grado de escuelas primarias urbanas. Su objetivo: brindar una secuencia lógica para el desarrollo de la originalidad en la producción de textos escritos, a partir del enfoque cognitivo, comunicativo y sociocultural y la adecuación didáctica del método de análisis discursivo-funcional.

Es importante el uso de los medios de enseñanza para el logro de la percepción total del modelo de texto que se va a producir. Entre ellos cabe mencionar el libro de texto de Lectura, hojas de trabajo, láminas, entre otros, que permitirán el desarrollo de un proceso de enseñanza-aprendizaje desarrollador en clases presenciales participativas donde predomine el protagonismo estudiantil.

Aplicación de la metodología propuesta en un sistema de clases

El sistema de clases que se presenta tiene el propósito de demostrar al maestro cómo llevar a cabo la tercera etapa para la implementación de la metodología teniendo en cuenta la adecuación del método discursivo-funcional con los procedimientos que se proponen para servir de soporte en la dirección del proceso de producción de textos escritos. Se sugiere que las clases pueden realizarse en un grupo multigrado de 5to-6to; también puede ser un grupo de 3ero-4to-5to-6to, según esté compuesto el grupo donde imparte clases el maestro.

Primer día 
Clase

Asunto: Producción de un texto escrito en versos.

Objetivo: Escribir un texto poético, a partir de un modelo de texto analizado.

Método: Trabajo independiente

Procedimientos: Análisis, observación, lectura en silencio, lectura oral: expresiva, selectiva, comparada.

Medios: Libro de texto de Lectura, hojas de trabajo.

Motivación

1. Actividades antes de la lectura del modelo de texto

a) Motivación: Se realiza a través del trabajo con los datos del autor y el título del texto, como un primer acercamiento al texto.

Preguntar:

- Expón los datos que encontraste sobre la vida y obra de la autora.

- Lee en silencio el título del texto.

- ¿Cómo clasificas la palabra libertad, según su función como clase de palabra y por su acentuación? Explica el porqué de cada clasificación.

- ¿Qué te sugiere ese título?

- ¿Quién o quiénes podrían ser los personajes de este texto? ¿Cómo crees que es o son?

El maestro permite que se establezca el intercambio oral entre los escolares y realiza el tratamiento inicial a la expresión oral y a la ortografía de algunas palabras en la pizarra.

b) Se trabaja con el vocabulario, pero ya el maestro pudo haber asignado la tarea de la búsqueda del significado de las palabras de difícil comprensión en su significado.

Vocabulario: vereda, encendido, cesar, polícromo, sombrí, leve, exaltados, aúreo, umbría, cúpula, frondosa, batí, contagiado, rebuznaba, violentos, rozaba.

El maestro debe escribir oraciones en la pizarra con las palabras subrayadas e indicar a los escolares que digan su significado. Se trabaja con los significados y la ortografía de algunas palabras, y de otras si es necesario.

c) Seguidamente, les presenta el asunto, los objetivos y los invita a leer en silencio el texto «Libertad».

Modelo de texto

\section{LIBERTAD}

Llamó mi atención, perdida por las flores de la vereda, un encendido pajarillo que, sobre el húmedo prado verde, abría sin cesar su preso vuelo polícromo. Nos acercamos despacio, yo delante, Platero detrás. Había por allí un bebedero sombrío, y unos muchachos traidores le tenían puesta una red a los pájaros. El triste reclamillo se levantaba hasta su pena, llamando, sin querer, a sus hermanos del cielo.

La mañana era clara, pura, traspasada de azul. Caía del pinar vecino un leve concierto de trinos exaltados, que venía y se alejaba, sin irse, en el manso y aúreo viento playero que ondulaba las copas. ¡Pobre concierto inocente, tan cerca del mal corazón!

Monté en Platero, y, obligándolo con las piernas, subimos, en un agudo trote, al pinar.

En llegando bajo la umbría cúpula frondosa, batí palmas, canté, grité.

Platero, entre las lejanas maldiciones de los chiquillos violentos, rozaba su cabezota peluda contra mi corazón, dándome las gracias hasta lastimarme el pecho.

Juan Ramón Jiménez

d) El maestro, posteriormente, presenta el asunto, los objetivos y los invita a leer en silencio el texto.

La maestra expresa que a continuación se identificarán con un modelo de texto, que les servirá para aprenderlo a escribir.

2. Actividades durante la lectura del modelo de texto

a) La maestra o un monitor realiza la lectura modelo. Después se realizan las siguientes preguntas de comprensión:

- ¿Qué impresión te ha causado la lectura? ¿Qué tipo de texto es? ¿Por qué lo has reconocido? 
El maestro hace un resumen acerca de la narración, los textos narrativos y sus partes, con énfasis en el relato.

b)Indica de nuevo la lectura, en silencio, del primer párrafo.

Pregunta:

- ¿Qué parte del relato representa este párrafo? ¿Por qué lo sabes?

- Subraya las palabras que utilizó el autor para describir al pajarillo, prado, vuelo, bebedero, muchachos y reclamillo. ¿Qué clase de palabras son? ¿Por qué lo sabes?

c) Indica de nuevo la lectura, en silencio, del segundo y tercer párrafos.

- ¿Qué parte del relato representan estos párrafos? ¿Por qué lo sabes?

- Narra, oralmente, los sucesos de esta parte.

d) Indica de nuevo la lectura, en silencio, del cuarto párrafo.

- ¿Qué parte del relato representa este párrafo? ¿Por qué lo sabes?

- ¿Cómo finaliza el relato?

Se orienta la lectura total oral del relato. El maestro indica la tarea para la casa que consiste en copiar el modelo de texto y la lectura en silencio de este.

Segundo día. Re-creación del modelo de texto

La segunda clase comienza rememorando la tarea del día anterior.

Los escolares muestran la copia del modelo de texto y el maestro corrige los errores que en cuanto a la caligrafía y la ortografía se hayan detectado.

El maestro los invita a realizar algunas actividades después de la lectura del modelo de texto.

a) La maestra invita a realizar la re-creación del modelo de texto de forma colectiva. Se va leyendo cada párrafo, y a la vez van cambiándolo por otro, pero a través de la cooperación en dúos. Los escolares, con la guía de la maestra, van determinando los rasgos del texto narrativo y sus partes. Se enfatiza en los recursos expresivos que ha innovado el autor para darle más belleza al texto. Realizan luego la búsqueda del significado de esos recursos y el análisis de la coherencia de las ideas que expresa el autor.

b) Indica lo siguiente:

Lee el primer párrafo.

- Interpreta la expresión: «... había por allí un bebedero sombrío».

- ¿Qué recurso expresivo es?

- Sustituye ese recurso por uno creado por ti.

- Interpreta la expresión: «... El triste reclamillo se levantaba hasta su pena,...».

- ¿Qué recurso expresivo es?

- Sustituye ese recurso por uno creado por ti.

Lee en silencio el segundo párrafo:

- ¿Qué te sugiere la expresión: «... La mañana era clara, pura, traspasada de azul...»?

- ¿Qué recurso expresivo es?

- Sustituye ese recurso por uno creado por ti.

Lee en silencio el tercer párrafo:

- ¿Qué te sugiere la expresión: «... Y los ecos respondían secos y sonoros, como en el fondo de un gran pozo...»?

- ¿Cuáles recursos expresivos aparecen en ella?

- Sustituye cada recurso por uno creado por ti.

Lee en silencio el quinto párrafo:

¿Qué te sugiere la expresión subrayada: «... Platero, entre las lejanas maldiciones de los chiquillos violentos, rozaba su cabezota peluda contra mi corazón, dándome las gracias hasta lastimarme el pechom?

- Sustituye cada recurso por uno creado por ti.

c) Los escolares expresan sus juicios, puntos de vista, valoraciones, establecen inferencias y aplican sus conocimientos. La maestra ofrece explicaciones, impulsos heurísticos para favorecer al escolar la invención de los recursos estilísticos en función de una creación literaria original. Luego, posibilita el intercambio acerca de los elementos que utiliza la autora para mostrar la originalidad del texto.

d) La maestra va copiando el texto en la pizarra. 
e) Una vez que se termina la re-creación colectiva del modelo de texto, la maestra propicia un diálogo sobre la libertad. Para ello la maestra se apoya en las siguientes actividades:

- ¿Qué significa la libertad para los seres animados?

- ¿Cómo yo caracterizo la libertad de los pioneros cubanos?

f) Después que los escolares han emitido sus ideas, el maestro indica como estudio independiente:

Escribe el relato como si fueras el narrador. Amplía los detalles: puedes contar cómo era el lugar, por qué estabas alli y cómo reaccionó la persona cuando te fuiste.

Texto re-creado colectivamente

«Todos merecemos la libertad»

Una mañana resplandeciente, en la que los pájaros cantaban con gran arrullo y revoleteaban alegremente por su lugar de estancia, en los parques y bosques, salí a dar un paseo por el barrio con uno de mis mejores amigos. Las aves de allí eran blancas como la nieve y su plumaje suave como un algodón. Tenían picos cortos y sus ojos de azabache brillaban mucho en las noches.

Les cuento que llegamos a una pequeña llanura verde y rociada. Nos aproximamos un poco adonde estaba una fuente cercana. Anteriormente, nos percatamos que ya los pájaros no estaban como antes, porque unos niños tenían puesta una red a varios de ellos.

Me quedé mirando a las nubes, y de repente las montañas se estremecieron. La pobre avecilla, reclamaba de una manera tan triste, que levantaba su pena. Mi compañero, al ver tal acto horrible, decidió hablar con los niños.

-Buenos días.

-Buenos días — respondieron.

— ¿Por qué tienen a estos pobres animalitos en cautiverio? - preguntó.

- Saben, estos son seres vivos que forman parte de nuestra madre naturaleza y hay que dejarlos en libertad para que puedan vivir como nosotros.

Al dejar claro todo esto, dejaron el camino abierto para los pajarillos. Y se fueron para otro espacio en donde pudieron hacer sus cosas libres y sin nadie que los molestara.

Desde ese día en adelante, nunca más volvieron a ser molestados por los muchachos ingratos y por otra parte, les agradecieron modulando sus cantos en armonía por dales nuevamente su paz.

Tercer día: Producción textual escrita individual

La maestra da inicio a la clase retomando la tarea del día anterior. Los escolares leen el informe escrito. La maestra pregunta:

- ¿Cómo se titula el texto leído en la clase anterior? ¿Cuál era su tema? ¿Qué tipo de texto es? ¿Cómo lo sabes?

Seguidamente, da a conocer el objetivo de la clase: escribir un texto narrativo, y orienta la consigna: Resalta la importancia de la libertad para todos los seres vivos a través de un texto narrativo real o ficticio para ser presentado en un taller de creación literaria en tu centro escolar.

Bajo la dirección del maestro, se precisan las condiciones emitidas en la situación comunicativa a través de una conversación: ¿Qué escribirán? ¿A quién lo escribirán? ¿Para qué lo escribirán? ¿Sobre qué escribirán?

Al comenzar la planificación del texto la maestra indaga acerca de los conocimientos que anteceden:

- ¿Qué se entiende por texto narrativo? ¿Qué partes lo conforman? ¿Qué tipos de textos narrativos conoces?

De forma colectiva, los escolares dan respuestas a las preguntas. La maestra copia en la pizarra que: El texto narrativo está estructurado por: introducción, desarrollo y desenlace. El cuento, la fábula, la historia, el relato, la anécdota, entre otras, son textos narrativos. Estos pueden ser ficticios o reales. Los escolares proceden a la elaboración de su plan y la escritura del título. La maestra va por los asientos corrigiendo los errores y dando impulsos heurísticos para el alcance por los escolares de un título sugerente.

La maestra orienta la redacción o textualización del texto narrativo. Cada escolar elabora su primer borrador, mientras la maestra va pasando por los asientos para controlar cómo van escribiendo y va 
brindando su ayuda, atendiendo a las características del tipo de texto. Les sugiere que vayan incorporando los recursos expresivos y lingüísticos creados por ellos. Atiende las diferencias individuales. Una vez finalizada la redacción o textualización, se orienta para la casa la revisión de la caligrafía y la ortografía del texto escrito y si es necesaria la elaboración de tantos borradores como sean necesarios.

Texto escrito por un escolar

«La libertad es el derecho de todos»

Una tarde muy soleada, en la que el sol, color de oro, alumbraba tanto mi país, decidí dar un paseo por el parque Plaza de Marte, ya que me encontraba acompañada de una amistad mía, que hace mucho tiempo no la había visto, por lo cual la invité a este lugar tan natural.

Sucedió que, al llegar, nos encontramos con dos pioneros, los cuales me comentaron que un adolescente estaba maltratando a un pequeño pajarito. Rápidamente, buscamos entre las dos hembras y los dos varones a ese animalito encarcelado.

Todo el tiempo escuchamos la melodía de su canto, sin embargo, no se escuchaba claramente, por el ruido que existía en ese pedacito de tierra. Aun, cuando pasó un tiempo no lo habíamos encontrado, pero cuando una niñita se acercó a nosotros, y nos ubicó sobre el lugar preciso donde se encontraban. ¡Qué alegría! A continuación, nos apresuramos tanto, que llegamos agotados, pero cumplimos nuestro propósito: encontrar al adolescente.

$\mathrm{Al}$ observar lo que mis propios ojos estaban reflejando, no lo podía creer, a raíz de lo que encarceló era un tocororo. Por eso, decidí explicarle que el tocororo es nuestra ave nacional, sus colores son iguales a los de la bandera y cuando esta ave se encierra puede hasta perder la vida.

El muchacho comprendió lo explicado, y en ese momento, lo liberó. Desde ese día, nunca más volvió a cometer esta injusticia, y propuso en su aula que el lema fuera: «Todos merecemos ser libres, es uno de nuestros derechos».

Cuarto día. Evaluación de los textos escritos con originalidad

Durante la revisión y ajuste del texto la maestra indica la lectura oral individual de su texto y va propiciando la búsqueda independiente por parte de cada escolar de sus aspectos positivos y sus errores, propiciando además las condiciones ambientales adecuadas para que los escolares se concentren y puedan emerger las ideas creativas con originalidad. Exige atención y una escucha responsable. Promueve el intercambio de trabajos entre los escolares con vista a socializar o corregir ideas entre ellos.

La maestra promueve la autoevaluación y brinda el apoyo con la siguiente guía: *Leo el texto. *Escribí el título. ${ }^{*}$ Me ajusté al tema. ${ }^{*}$ Creé un texto con singularidad estilística y belleza textual. *Tuve en cuenta las características del texto seleccionado. ${ }^{*}$ Respeté la concordancia entre sustantivo-adjetivo y sujeto-verbo. *Expresé las ideas de forma clara y precisa. *Escribí sin errores ortográficos.

Para la coevaluación los indicadores son: *Leyó el texto. *Escribió el título. *Se ajustó al tema. *Creó un texto con singularidad estilística y belleza textual. *Tuvo en cuenta las características del texto seleccionado. ${ }^{*}$ Respetó la concordancia entre sustantivo-adjetivo y sujeto-verbo. *Expresó las ideas de forma clara y precisa. ${ }^{*}$ Escribió sin errores ortográficos.

La maestra, después de efectuada la evaluación de los textos escritos por los escolares, orienta como tarea: El cuenta cuentos. Pide a los escolares que en sus casas escriban un cuento corto cuyo tema sea la libertad, del cual pudieran hacer dibujos o figuras referidas. Luego, la maestra recoge los trabajos para revisarlos, y en una clase hará la revisión colectiva; cada escolar leerá su cuento para conocer el contenido de los demás y elaborar de cada uno un resumen, destacando los personajes principales y secundarios, así como el tema del texto.

Se aplica la evaluación sistemática de las actividades desarrolladas por los escolares y de sus destrezas comprender, analizar y construir textos con diferentes intenciones comunicativas y estilos funcionales, en los cuales demuestren la escritura de textos con originalidad.

Se realizó una consulta a especialistas con la finalidad de recoger los criterios a través de una encuesta individual, sobre la factibilidad de la instrumentación de la metodología en la práctica educativa. Para ello se consideraron los posibles especialistas a partir de una selección de 10 docentes de las provincias Santiago de Cuba, Guantánamo y Las Tunas que están relacionados directamente con 
la práctica pedagógica de la enseñanza de la lengua materna en centros de Educación Superior y la Educación Primaria, ya sea como directivos, profesores o investigadores.

Los criterios resultaron propicios. Consideraron que los aportes teóricos y prácticos de la investigación están a tono con los cambios que se operan en la práctica pedagógica actual, por lo que la estrategia didáctica que se aporta resulta necesaria, pues se ofrecen respuestas a las demandas que se deben alcanzar para el logro de un escolar-escritor creativo para producir textos escritos con originalidad.

Destacaron el valor psicopedagógico de la propuesta y su viabilidad para ser implementada en el proceso de enseñanza-aprendizaje de la asignatura Lengua Española en el quinto grado. Expusieron que la metodología resulta interesante y novedosa, en tanto articula de manera coherente los procederes metodológicos en las diversas acciones que la integran, lo que favorece el mejoramiento del proceso de enseñanza-aprendizaje de la producción de textos escritos, a partir de la interacción de maestro, escolar y grupo.

Sugirieron la posibilidad de sistematizar su instrumentación en otros contextos la propuesta, a partir de su divulgación con maestros de otros grados, por lo que es necesaria una alta preparación teórico-metodológica del maestro para que se alcance un alto grado de independencia cognoscitiva en los escolares durante el desarrollo de la originalidad en la producción de textos escritos.

Las aportaciones de los especialistas tuvieron argumentos sólidos hacia su reconocimiento por la validez de la lógica integradora de la metodología propuesta en la investigación y su basamento en los nuevos postulados de la didáctica de la lengua. Consideraron que se contribuye a la formación y desarrollo de los indicadores detallados para el desarrollo de la originalidad en la producción de textos escritos por los escolares de las escuelas primarias rurales. Las recomendaciones recibidas se tuvieron en cuenta y se realizaron las modificaciones que se consideraron.

\section{Discusión}

En Cuba, se han realizado varias tesis de maestría y de doctorado sobre el tema que se investiga. Se destaca la tesis de maestría de la enseñanza media superior de A. M. Abreu León (1998) y, en el ámbito internacional, relucen los estudios acerca de la creatividad en la producción de textos escritos en la Educación Primaria de R. Caldera (2006), A. Silvera (2016). B. Y. Guzmán, J. P. Bermúdez (2018), que brindan proposiciones didácticas y exigencias para la escritura creativa.

El diagnóstico fáctico efectuado con la aplicación de una prueba pedagógica de entrada, entrevistas (a escolares y a maestros) y observaciones a clases revelan:

- Limitaciones teórico-metodológicas de algunos maestros para alcanzar la asimilación del modelo de texto original en los escolares durante un proceso integrado de producción de textos escritos.

- Insuficiencias en la producción de textos escritos en los escolares de quinto grado, que se expresan en la comprensión textual, el uso de los elementos de coherencia, la pobreza de las ideas y la extensión del texto, así como en la originalidad con un marcado índice de pobreza en el poder imaginativo. Ningún escolar (0\%) tiene el nivel alto (A), solo 3 alumnos están en el nivel medio (M) para un $15 \%$ y 17 se declaran con un nivel bajo (B), para un $85 \%$.

Desde el diagnóstico causal se pudo determinar:

- Limitado conocimiento de algunos maestros y escolares acerca del concepto originalidad, con los indicadores esenciales para su evaluación en la producción de textos escritos.

- Desatención metodológica y discursiva en algunos maestros, así como empleo de formas tradicionales durante la clase de Lengua Española que limitan el desarrollo de la originalidad en la producción de textos escritos mediante la contextualización y socialización.

- Estilos de aprendizaje comunicativo en modelos unidireccionales de comunicación, que no permiten la interacción durante el discurso.

Se aprecia, en la aplicación de los instrumentos, una buena disposición de los escolares, el maestro y las familias para resolver las insuficiencias.

Las citadas limitaciones manifiestan una contradicción que surge entre el enfoque actual del tratamiento de la producción de textos escritos y las exigencias para el desarrollo de la originalidad en dicho proceso en los escolares.

Los resultados del diagnóstico de entrada demostraron las insuficiencias que existen en la enseñanza-aprendizaje de la producción de textos escritos y ubicaron el objetivo de la metodología, 
ratificando el valor de un enfoque que integra los procesos funcionales: comprensión, análisis y construcción en la enseñanza de dicho contenido.

Se efectuó un análisis de la concepción del proceso de enseñanza-aprendizaje de la producción de textos escritos en el programa de quinto grado de la Educación Primaria. Se consideró que no es necesario eliminar ningún tipo de texto para producir de forma escrita de los que aparece en dicho programa, pero sí es necesario el aumento de las horas clase en función del desarrollo de la originalidad con la forma de presentación que se presenta en la metodología que se propone.

Quedó demostrado que la producción de textos escritos como proceso integrado, a partir de la necesidad del desarrollo de la originalidad en los escolares de quinto grado, se puede hacer la presentación del objetivo atendiendo a la habilidad escribir en la primera clase del sistema. Se definieron los indicadores para el desarrollo de la originalidad en el proceso de enseñanza-aprendizaje de la producción de textos escritos desde el enfoque cognitivo, comunicativo y sociocultural, con la propuesta de procedimientos que responden a la adecuación del método de análisis discursivo-funcional y al desarrollo de destrezas para la comprensión, análisis y construcción de textos.

Se evidenció la necesidad de la búsqueda de una alternativa para el proceso de enseñanza-aprendizaje de la producción de textos escritos, que permita la recuperación de estilos de trabajo participativos, donde prevalezca la precisa relación escolar-escolar, maestro-escolar y que estos se manifiesten con independencia cognoscitiva, en las clases con procedimientos tradicionales y otros derivados de una adecuación del método de análisis discursivo-funcional del enfoque cognitivo, comunicativo y sociocultural.

Se procedió a la presentación y explicación de la metodología para el desarrollo de la originalidad en la producción de textos escritos, la cual tiene como objetivo: Ofrecer una secuencia lógica para el desarrollo de la originalidad en la producción de textos escritos en los escolares de sexto grado, a partir del enfoque cognitivo, comunicativo y sociocultural y la adecuación didáctica del método de análisis discursivo-funcional.

Se seleccionaron los modelos de textos a analizar en cada unidad del programa, atendiendo a que estuvieran dotados de recursos esenciales para que los escolares pudieran asimilar la originalidad. Se tuvo en cuenta que en cada unidad se midieran los indicadores para el desarrollo de la originalidad en diferentes tipos de texto en prosa y en versos, en un proceso integrado de producción de textos escritos.

En la implementación de la metodología en las clases se partió del objetivo como rector del proceso, enunciado en cada unidad y actividad docente en función de lograr la transformación deseada para el desarrollo de la originalidad en la producción de textos escritos por los escolares. El objetivo se caracterizó por ser instructivo y desarrollador orientado a la aprehensión de conocimientos, la formación de convicciones y rasgos de la personalidad. Hubo atención a la formación de habilidades que respondieron al desarrollo apropiado de la originalidad en la producción de textos escritos, con el adecuado uso de la lengua como medio de comunicación y se atendió a la diversidad tomando a consideración los resultados del diagnóstico del grupo.

$\mathrm{Al}$ trabajar los modelos de textos para el desarrollo de la originalidad en la producción de textos escritos en las clases se consideró el entrenamiento informativo que exige la comprensibilidad de un modelo de texto y que se corresponde con la identificación del modelo de texto que se va a producir, la profundización en el tipo de texto, que es eficaz para la comprensión y aprendizaje de sus estructuras para poder realizar el esquema textual, potenciando en los escolares, los procesos psicológicos tales como: perceptivos, de decodificación, inferenciales, procesamiento sintáctico y procesamiento semántico. Ello exigió la apropiación informativa, su utilización y la evaluación de esta.

Se logró que la maestra les propiciara a los escolares la construcción de una representación del significado del texto a través del trabajo con elementos paratextuales e intertextuales. Mediante la recreación del modelo de texto, de manera colectiva, pudieron construir un modelo sobre la base de uno ya creado, considerando el análisis de cada una de sus partes fundamentales, sus rasgos característicos, sus recursos fono-estilísticos, la morfosintaxis estilística, la selección léxica, la serie psicopersonal, autobiográfica, el contexto sociocultural y estético, las relaciones intertextuales, entre otros. De esta manera, se manifestó el entrenamiento constructivo durante el proceso de la producción de textos escritos.

$\mathrm{Al}$ contrastar los resultados de la prueba pedagógica de salida con la de entrada se muestra que en los dos indicadores de la originalidad solo 5 alcanzaron nivel alto (A) para un $25 \%, 10$ están en el nivel medio (M) para un $50 \%$ y 5 en el nivel bajo (B) que representan el $25 \%$, gracias al desempeño 
consecuente de la maestra sobre la base del tránsito de la preparación elemental para la apropiación de la innovación y a la demostración de la preparación didáctica que se prevé en la metodología propuesta.

La dinámica de la evidencia encaminó a los escolares a ir captando la originalidad en sus tres dimensiones:

- Originalidad interior: constituye la interacción con el texto; se usan técnicas para el desarrollo del pensamiento-lenguaje y se desentrañan, del modelo de texto, los recursos cargados de innovación.

- Originalidad colectiva: incluye técnicas para el desarrollo de procesos del grupo en la reconstrucción de los significados del modelo de texto, con énfasis en los recursos para la innovación.

- Originalidad técnica: es el desarrollo de la expresión individual con independencia cognoscitiva para la creación de los recursos necesarios para el logro de la innovación en el texto escrito.

La metalingüística posibilitó que los escolares operaran de manera premeditada su comportamiento lingüístico con el propósito de hacerlo con más certeza. Desde esta visión, los escolares escritores independientes y conscientes dieron muestra de lo que hay que hacer, cómo se debe hacer y la forma de controlarlo mientras se efectúa el aprendizaje.

\section{Conclusiones}

La metodología aplicada para el desarrollo de la originalidad en la producción de textos escritos por los escolares de la escuela primaria rural ha sido beneficiosa para la divulgación de un aspecto importante que el maestro tiene que evaluar en la producción de textos escritos de los escolares y que no aparece en ninguno de los documentos normativos ni bibliografía que está a su alcance orientaciones metodológicas sobre la evaluación de la originalidad, procedimientos metodológicos para estimular la originalidad a través de las clases, entre otras.

Con la aplicación de las cuatro etapas se pretendió diagnosticar las debilidades y potencialidades del maestro para el desarrollo de la originalidad en la producción de textos escritos en los escolares de quinto grado, adiestrar al maestro para la implementación de la metodología, contribuir al logro de un desempeño metodológico del maestro con ajuste al desarrollo de la originalidad en la producción de textos escritos, atendiendo a los pasos metodológicos, la estimulación de las motivaciones intrínseca y extrínseca (Amabile, 1989), el establecimiento de la adecuación del método discursivofuncional a través de los procedimientos propuestos, contenidos, medios, evaluación y organización de las acciones que se ejecutarán por parte de la maestra, así como evaluar los resultados de la metodología para el desarrollo de la originalidad en la producción de textos escritos de los escolares de quinto grado.

En esta línea de pensamiento, la metodología que se aplicó es flexible por ser susceptible a mejoras, modificaciones atendiendo a las potencialidades de los escolares y a los ajustes de su alcance, de acuerdo con los problemas a resolver, sin perder de vista su propósito. También, se considera desarrolladora debido a que se proyectó para un proceso de enseñanza-aprendizaje desarrollador (P. Rico et al, 2006), donde se reconoce cómo cada escolar buscó de manera independiente los recursos para apropiarse de la cultura en un nivel de complejidad ascendente y ello le exigió un comportamiento responsable para la construcción, protección y re-creación de esa cultura a favor de su crecimiento personal y de la sociedad. Ello permitió la atención de la formación cognitiva, afectiva y motivacional por parte del maestro.

Se ha contribuido a divulgar un material didáctico que podría ser publicado en un Plan Editorial de Educación. Serán beneficiarios no solo los maestros y escolares de la Educación Primaria. Constituye un material didáctico de gran utilidad para la formación inicial de maestros, con énfasis en las asignaturas de Lenguaje y Comunicación y Didáctica de la Lengua Española; de ahí su alto valor para la conformación de una teoría didáctica, flexible y creadora.

\section{Agradecimientos}

A todos los que de alguna manera están presentes en este resultado final, nuestro sincero y eterno agradecimiento. 


\section{Referencias}

Abreu, A. M. (1988). La Creatividad en la construcción textual: vías para su desarrollo en alumnos de 7 mo grado. Tesis presentada en opción al título de Máster en Ciencias de la Educación, Universidad de Ciencias Pedagógicas Frank País García, Santiago de Cuba.

Amabile, T. M. (1989). Growing up creative. New York: Crown.

Arroyo, R. 1. (2015). La escritura creativa en el aula de Educación Primaria. Orientaciones y propuestas didácticas. Trabajo de Fin de Grado de Maestro en Educación Primaria. Universidad de Cantabria, España.

Caldera, R. \& Escalante D. (2008). Escribir en el aula de clase: Diagnóstico en sexto grado de Educación Básica. Disponible en: http://www.scielo.org.ve/scielo.php?script=sci_arttext\&pid=S079. [Consultado: 25 de noviembre 2008].

Díaz, M. F. (2012). Modelo didáctico del desarrollo de la originalidad en la producción de textos escritos por escolares de sexto grado de la Educación Primaria. Tesis en opción al grado científico de Doctor en Ciencias Pedagógicas, UCP Frank País García, Santiago de Cuba.

Diccionario electrónico de la Real Academia (2010). España: (s. n.).

Domínguez, I. (2006). Modelo didáctico para la orientación del proceso de construcción de textos escritos. Tesis en opción al grado científico de Doctor en Ciencias Pedagógicas. UCP Enrique José Varona. Ciudad de la Habana.

Guzmán, B. Y. \& Bermúdez, J. P. (2018). Escritura creativa en la escuela. Infancias Imágenes, 18(1), (enero-junio 2019), pp. 80-94. Recuperado de: http://revistas.udistrital.edu.co/ojs/index.php/infancias. doi: 10.14483/16579089.1226.

Olivares, A. (2015). Escritura emocional. Recuperado el 20 de Agosto de 2015 de: https:/ / escrituraemocional.wordpress.com/.

Rico, P. (et al). (2006). Proceso de enseñanza aprendizaje desarrollador en la escuela primaria. Teoría y Práctica. La Habana: Editorial Pueblo y Educación.

Roméu, A. (et al). (1997). Lengua materna: cognición y comunicación. IPLAC, La Habana: (s. n.).

Roméu, A. (2003). Teoría y Práctica del análisis del discurso. Su aplicación en la enseñanza. La Habana: Editorial Pueblo y Educación.

Roméu, A. (2007). El enfoque cognitivo, comunicativo y sociocultural en la enseñanza de la lengua y la literatura. La Habana: Pueblo y Educación.

Silvera, A. (2016). Producción de textos escritos en estudiantes del quinto grado de primaria en la institución educativa Francisco Bolognesi Cervantes. Tesis para optar el título de Licenciado en Educación Primaria, Universidad San Juan de Lurigancho, Bogotá.

Vigotsky, L. S. (1979). El desarrollo de los procesos psíquicos superiores. Barcelona: Grijalbo. 